\title{
How (and How Not) to Object to Objects: Developments in Structural Realism
}

Review of Structural Realism: Structure, Object and Causality, eds. Elaine M. Landry and Dean P. Rickles, The Western Ontario Series in Philosophy of Science 77, Springer, hardback, 209 pages.

Kerry McKenzie, University of Leeds, Leeds, LS2 9JT, UK.

This is the penultimate draft of a review that came out in Metascience (2012). Please only cite the final version.

'Structural Realism: Structure, Object and Causality' is a collection of new essays on structural realism that grew out of a workshop held at the foot of the Canadian Rockies in the summer of 2007. With 12 essays covering three grand themes within structuralism - namely, the formal frameworks most appropriate to structuralism, the structuralist metaphysics of objects and relations, and the incorporation of modality within it - tracing the conceptual links between the contributions can be challenging at times. Nevertheless, this collection provides a valuable cross-sectional view of the contemporary state of the field, and especially so when taken together with Bokulich and Bokulich's recent (2011) edition on 'Scientific Structuralism'. In what follows, I shall put the papers on formal frameworks for structuralism to one side and focus upon some of the more metaphysical topics that are dealt with in the course of the volume, and in particular those of identity, intrinsicality, ontological priority and modality.

Perhaps the most significant individual paper is Brading and Skiles's 'Underdetermination as a Path to Structural Realism'. As the title suggests, this work concentrates upon the argument for eliminative structuralism that is predicated upon the alleged underdetermination of object identity. This argument has historically been central to the work of French and Ladyman, and continues to be so in the case of the former at least; indeed, in this very volume French again states that the "mysterious nature" that structuralism attributes to objects issues from their allegedly undetermined identity profile. Despite it 
being over a decade since Ladyman first proposed it, however, the argument has until now remained informal. By breaking it down into its separate strands, Brading and Skiles are able to subject the argument to sustained and methodical scrutiny, and thus develop the criticisms that have already been made of it by, amongst others, Saatsi (2010) and Chakravartty (2003).

Brading and Skiles' primary concern is with the premise of the underdetermination argument - as they reconstruct it - which states that "object-oriented realists are committed to objects (that are ontologically basic) having determinate individuality profiles: [meaning that] (i) there is a fact of the matter about whether an object is an individual or not, and (ii) if it is an individual, there is a fact of the matter about how, precisely, it is individuated" (pp. 100-101). Their main contentions in this paper are that the support offered for this idea is insufficiently compelling, and that there is, on the contrary, an alternative notion of object that is both naturalistically acceptable and lacking in a determinate individuality profile. With regard to the first contention, the authors argue that the brunt of the evidence French and Ladyman provide for the premise is historical in character, and based solely upon physicists' handwringing over the significance of the quantum statistics and the apparent loss of individuality that they imply. However, they go on to speculate that had these physicists been aware of the (by now well-known)gument that the statistics do not demand but only permit the non-individuals view, they may well have drawn the conclusion that "the shift implied by quantum mechanics is not from individuals to non-individuals, but from individuals to particles for whom the categories of individual and non-individual do not apply" (p. 103). Relatedly, and with regard to the second contention, they argue that the 'law-constitutive approach' to objects, already discussed in a series of papers by Brading, represents a third and seemingly naturalistically admissible notion of an object, from which identity considerations may intelligibly be detached. (They note furthermore that, in places, French and Ladyman appear to endorse just such a notion themselves, particularly in their discussions of structuralism's Cassirerian legacy.) 
This argument of Brading and Skiles will have a resonance for those, like me, who have structuralist sympathies but have always found it somewhat puzzling as to why the possession of determinate identity conditions is continually insisted upon, by French and (perhaps) Ladyman, as "the most fundamental ontological characteristic" of objects and as such a sine qua non of commitment to them. Indeed, it is difficult to think of what arguments drawn from modern metaphysics one could cite in support of this claim. Thus while one could object that Brading and Skiles' assertion (in Section 5.3.3) that all that is metaphysically required of objects is their countability simply begs the question against French and Ladyman, it seems to me that the burden of proof is upon the latter to argue that determinate individuality conditions are required in addition to this.

Nonetheless, there are some aspects of Brading and Skiles' argument that would arguably benefit from polishing up. For one, the argument is somewhat ambiguous between the idea that the failure of a physical theory to determine whether a given physical object is an individual or a non-individual would imply that it is positively indeterminate as to whether it is either, and the idea that such a failure would imply that questions of individuality are simply irrelevant to naturalistic metaphysics. While this difference might seem a mere quibble, there is arguably room for a third individuality category for objects in which individuality profiles are relevant but positively indeterminate, and which may change the moral of the argument. Furthermore, I did wonder why they insisted on working with such a strong notion of an individual - namely, as an object that "can be named such that it may be uniquely re-identified at later times and across possible worlds" (p. 106) - which would just seem to entail that quantum particles (at the very least) are unambiguously not individuals. More importantly, however, I think that one may readily anticipate how French himself might respond to the points raised. At the root of this response is the fact that the notion of a 'law-constituted' object is, as it stands, arguably just metaphorical, and indeed Brading and Skiles themselves happily admit that the task of spelling out exactly what it portends will be a "much bigger project" which they can barely touch upon in their paper. But I expect French to contend that, insofar as the notion is eventually to be rendered perspicuous, formal 
regimentation will at some point be required, and at that point the basic issue Brading and Skiles claim may be circumvented will have to be faced up to all over again. After all, French will argue, without some prior stance on the identity conditions of the objects of one's theory, one cannot even know which logic to use. (His debate with Saunders over individuality is, after all, partially over choices of regimentation.) Exactly how Brading and her co-workers would choose to respond to this point might draw on detailed issues in the philosophy of logic that I cannot helpfully speculate upon; but perhaps the path taken would rather be to suggest that French simply has too great a set of expectations regarding the tasks that the philosopher of science must burden herself with. Indeed, this tussle over the demands of naturalism is a theme that is echoed in Landry's paper in this volume, a paper which draws heavily on her own work with Brading; but I will forgo discussion of Landry's paper here.

Brading and Skiles' essay explicitly serves as the jumping-off point for Nounou's contribution, 'Kinds of Objects and Varieties of Properties'. Although Nounou perhaps goes further than is warranted in holding that the former essay demonstrates that "the issue of individuation has been rendered irrelevant" ( $p$. 122 ) to structuralism, she is surely correct to suggest that other questions of the intrinsic natures of objects besides that of their identity deserve more attention than they have had hitherto. She thus goes on to argue that the principal task for structuralists is to demonstrate that the seemingly intrinsic qualitative properties of objects can be understood in suitably structural terms and, after suggesting that the familiar metaphysical categories of intrinsic and extrinsic are too course-grained to be especially helpful here, she indicates some of the subtleties that are likely to be involved in this task. A lot of the emphasis here as in structuralism as a whole - is on the notion of symmetry structures and the problems of securing the priority of such structures over the relevant irreducible representations (and hence particles), and as such there are clear links with the recent work of Wolff (2011). However, certain aspects of Nounou's presentation strike me as somewhat puzzling. In particular, it isn't clear to me why she has chosen the taxonomy of relational properties as the analysans of putatively 
intrinsic properties that she has done, nor whether it is intended to be exhaustive; indeed, since quantum field theory is explicitly in the picture here, there are intuitively more immediate ways in which one could problematize the notion of intrinsicality (for example, through considerations of the renormalization group). More seriously, however, her presentation of ontological priority (specifically, of ontological dependence) is ambiguous throughout the paper, and different analyses of it will likely change the truthvalues of her claims.

Since Chakravartty's paper, 'Ontological Priority: The Conceptual Basis of NonEliminative, Ontic Structural Realism' focuses squarely upon clarifying the notion of priority that is appropriate to non-eliminative structuralism, one might hope that this contains exactly what is required to remedy the latter problem. (The non-eliminative version of structuralism is, I might underscore, possibly the only one left if the underdetermination argument fails in its ambitions, as Brading and Skiles of course allege.) However, it is not clear to me that Chakravartty's piece will help fill the lacunae in Nounou's argument. Put (over-)simply, Chakravartty's argument is that non-eliminative structuralism requires the existence of objects with at least some putatively intrinsic properties (on pain of collapsing into eliminativism), but "the only well-developed option on extant views that places significant emphasis on relations" in connection with questions of intrinsic nature is the dispositionalist essentialist view of properties (p. 194). This view, however, cannot ground the sought-for dependence of intrinsic natures on relations, or so Chakravartty claims. But even putting aside my suspicion that Chakravartty is conflating identity dependence with existential dependence in his argument for the latter conclusion, there arguably is an alternative extant view in which intrinsic properties may plausibly be understood as dependent upon relations - namely, the symmetry group-based approach to particle properties that is discussed by Nounou. Thus while Chakravartty's discussion does bring out important nuances in the concept of priority that remains ambiguous in Nounou's piece, the two discussions do not quite manage to dock with one another - or at least not as they stand here. It 
therefore seems that structuralists will need to bang heads together some more if they are to more fully develop this unquestionably central plank of their metaphysical scheme.

The metaphysical issue that is most vaunted in this collection, however, is arguably neither intrinsicality nor priority but rather the accommodation of modality (including causality) into structuralist metaphysics. Nevertheless, I am unsure that it is this that will prove to be the most lasting contribution that the volume makes to the structuralist literature. The two pieces explicitly directed at issues of modality are those of Psillos and of Berenstain and Ladyman; although Chakravartty's piece is grouped together with these, its contact with modality is less explicit. But while Berenstain and Ladyman provide a robust and wide-ranging survey of arguments for realism about nomological modality, the focus is very much on the relationship between modality and scientific realism in general; while that is clearly very relevant to structuralism, whether the nitty-gritty of structural realism poses any special issues in this context is something of a side issue here. And while Psillos' paper constitutes a highly focused attempt to analyze certain modal issues specific to structuralism from a grassroots metaphysical perspective - in part, by discussing how Armstrong's notion of structural universals might be thought to be promising here - I cannot help but feel that he may be making things simultaneously more easy and more difficult for himself than he needs to. He perhaps makes things too difficult by considering structures in a highly abstract fashion, and in so doing misses that the structures often of concern in this field are (as Nounou has reminded us) symmetry structures, which arguably relate to concepts of modality in an almost trivial way; such structures, after all, typically describe structural features of laws. But he may also make things too easy by building parts of his argument around the rather caricatured presentations of molecules that may be found in discussions of Armstrongian structural universals - a notion which is arguably suffused with all manner of classical assumptions, and thus with those same sorts of assumptions that structuralists claim obsolesce many extant discussions of nomological modality. While such an obsolesence claim must of course be substantiated, to the extent that Psillos' discussion focuses on a very classical 
notion of structure it remains unclear exactly which portions of it will ultimately be regarded as relevant, at least by structuralists themselves.

I stress again that there is a whole set of issues that feature centrally in this book - namely, the issue of what formal framework(s) are most suitable for structural realism - that I have not touched upon here; nor have I even covered all of the papers that do directly engage with metaphysics. But with respect to the metaphysical topics that I did bring to the fore, there is much in this collection that has the potential to move the debate forward through careful re-assessment its roots, and in the process shift the emphasis towards those concepts that have not so far received the attention that they arguably deserve. In any case, having the various and sometimes divergent positions gathered together in one place will no doubt help followers of structuralism stay oriented within the shifting sands of this subject, and we may value collections such as these for that more modest reason as well.

*With thanks to all at the Leeds philosophy of physics reading group.

\section{References}

Bokulich, Alisa and Peter Bokulich. 2011. Scientific Structuralism. Boston Studies in the Philosophy and History of Science, Vol. 281.

Chakravartty, Anjan 2003. The Structuralist Conception of Objects. Philosophy of Science, 70: 867-878.

Saatsi, Juha. 2010. 'Whence Ontic Structural Realism?. In EPSA Epistemology and Methodology of Science: Launch of the European Philosophy of Science Association, eds M. Suárez, M. Dorato and Miklos Rédei, (pp. 225-265). Dordrecht: Springer.

Wolff, J 2011 Do Objects Depend on Structures? British Journal for the Philosophy of Science. doi: 10.1093/bjps/axr041 
